\title{
Modelagem Matemática de um Conversor Buck
}

\author{
Ayoanma C. de Azevedo Erick F. da Costa* João Lucas de O. Torres \\ Vandilberto P. Pinto \\ Curso de Engenharia Elétrica - Universidade Federal do Ceará - Campus Mucambinho Sobral - Rua \\ Estanislau Frota, S/N - Centro CEP: 62010-560 Sobral - Ceará \\ E-mail: ayoanma.c@hotmail.com erickfrotac@gmail.com joao.lucas.torres@gmail.com \\ vandilberto@yahoo.com.br
}

\section{RESUMO}

Conversores são amplamente utilizados em projetos de circuitos eletrônicos. Em muitos casos é necessário rebaixar uma tensão, como no caso da bateria de um celular que tem uma tensão maior que a dos componentes que esta precisa alimentar. Em outros casos é necessário elevar a tensão, como nos casos de chips que alimentam uma placa de circuito. Este projeto foca a modelagem matemática do conversor Buck, um conversor DC-DC abaixador.

O conversor Buck converte um nível de tensão contínua para uma tensão também contínua, porém com um nível menor. Este circuito é composto por um indutor, um capacitor, um resistor, um diodo e uma chave que pode ser implementada por um transistor. A Figura 1 (a) mostra o circuito do conversor Buck de forma simplificada. Com o chaveamento, a tensão vista pela carga é a tensão média da onda gerada pelo chaveamento. Dessa forma, o duty cycle (D) do chaveamento controla a tensão vista pela carga. $\mathrm{O}$ duty cycle é dado por:

Eq.01

$$
D=V_{o} / V_{S}
$$

Onde: $D=$ Dutycycle, $V_{o}=$ Tensão média (Tensão vista pela carga), $V_{S}=$ Tensão de alimentação.

As duas posições da chave podem ser substituídas por um botão e um diodo, como na Figura 1 (b) e (c). Quando a chave está fechada a fonte $\left(V_{s}\right)$ alimenta o circuito, carregando o capacitor e alimentando a carga. Deve-se observar que o nesse intervalo de chave fechada o diodo está em corte. A Figura 1 (b) mostra a energização do circuito para a chave fechada.

Quando a chave abre, a fonte de tensão deixa de alimentar a carga, porém o indutor atua forçando a corrente a permanecer constante. $\mathrm{O}$ capacitor descarrega fazendo a corrente passar pelo diodo fechando a malha, como pode ser visto na Figura 1 (c).

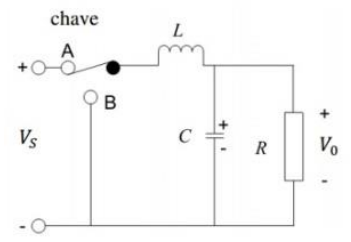

(a)

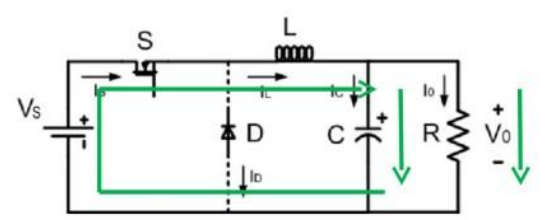

(b)

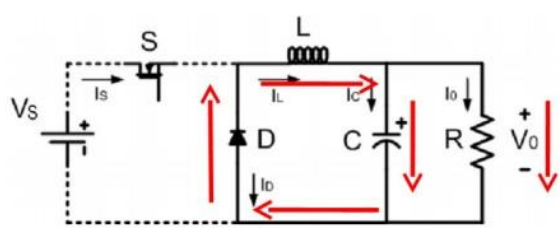

(c)

Figura 1 - (a) Circuito Simplificado do Conversor Buck e suas Etapas de Chaveamento: (b) Diodo em Corte e (c) Diodo em Condução.

Relacionando Eq. 01 com as equações de corrente no indutor e tensão no capacitor, assim como mostrado em [1], chega-se a:

Eq. 02

$$
L \geq \frac{D(1-D) V_{S}}{\Delta I_{L} f_{C}}
$$

Eq. 03

$$
C \geq \frac{\Delta I_{L}}{8 \Delta v_{c} f_{c}}
$$

Onde: $L=$ indutância, $\Delta I_{L}=$ variação na corrente do indutor, $f_{c}=$ frequência de chaveamento, $C=$ capacitância, $\Delta v_{c}=$ variação na tensão de saída.

Analisando Eq. 02 pode-se observar que há uma relação entre o indutor, o duty cycle e a tensão de alimentação. Como esses três elementos têm valores fixados, consequentemente o valor da tensão na carga também será fixo. Dessa forma, um conversor Buck apresenta valores 
fixos para tensão de entrada e tensão de saída, pois o mesmo depende dos componentes do circuito.

Um conversor Buck normalmente tem valores fixos de entrada e saída de tensão. Foi escolhido o modelo matemático de Vopérian, pois este lineariza o sistema, simplificando a matemática do Buck e fazendo com que a tensão de saída seja controlável em uma determinada faixa e não mais fixa. Neste modelo considerou-se a tensão de entrada constante e o duty cycle variável. A função de transferência para esse sistema, segundo [2], é dada pela Eq.04.

Eq.04

$$
J(s)=\left[V_{g} \cdot \frac{R}{\left(R+R_{S e}\right) \cdot L \cdot C}\right] \frac{\left(R_{s e} \cdot C\right) \cdot s+1}{\left\{s^{2}+\left[\frac{\left(R \cdot R_{L}+R \cdot R_{s e}+R_{L} \cdot R_{s e}\right) \cdot C+L}{\left(R+R_{S e}\right) \cdot L \cdot C}\right] s+\left[\frac{R+R_{L}}{\left(R+R_{S e}\right) \cdot \cdot \cdot C \cdot}\right]\right\}}
$$

Para a implementação do circuito, alguns valores do projeto devem ser definidos. Estes são: frequência de chaveamento $(\mathrm{fc})=30 \mathrm{kHz}$; potência de saída $(\mathrm{Po})=15 \mathrm{~W}$; tensão de entrada $(\mathrm{Vs})=24 \mathrm{~V}$; carga média (virtual) $=12,15 \Omega$; duty cycle médio $=56,25 \%$; tensão de saída média $=13,5 \mathrm{~V}$; variação máxima de corrente no indutor $(\Delta \mathrm{IL})=0,33 \mathrm{~A}$; Variação máxima da tensão na saída $(\Delta \mathrm{Vo})=0,83 \mathrm{~V}$. Estes valores são definidos pelos objetivos do projeto.

A partir das definições acima, chega-se aos valores de indutância e capacitância pela Eq.02 e Eq.03. Através destas equações chegou-se a $\boldsymbol{L}>0.5966 \mathbf{m H}$ e $\boldsymbol{C}>\mathbf{1 3 . 0 2} \boldsymbol{\mu F}$. Foram então utilizados um indutor de $3.3 \mathrm{mH}$ e um capacitor de $33 \mu \mathrm{F}$. A partir dos valores calculados e dos valores definidos, desprezando as resistências parasitas, chega-se a Eq. 05 da função de transferência a partir da Eq. 04:

Eq.05

$$
J(s)=\frac{3,102 \times 10^{8}}{s^{2}+3159 s+2,585 \times 10^{7}}
$$

A Figura 4 (a) mostra a simulação do circuito Buck rebaixando a tensão a 56,25\% do valor imposto $(24 \mathrm{~V})$. A Figura 4 (b) mostra a leitura do osciloscópio feita a partir do circuito montado. Como o tempo de transitório é muito pequeno (milissegundos), não é possível vê-lo no osciloscópio.

Em posse da função de transferência é possível posteriormente utilizar um controlador para reduzir o overshoot, modificar o tempo de acomodação e não perder a referência quando imposto a distúrbios.

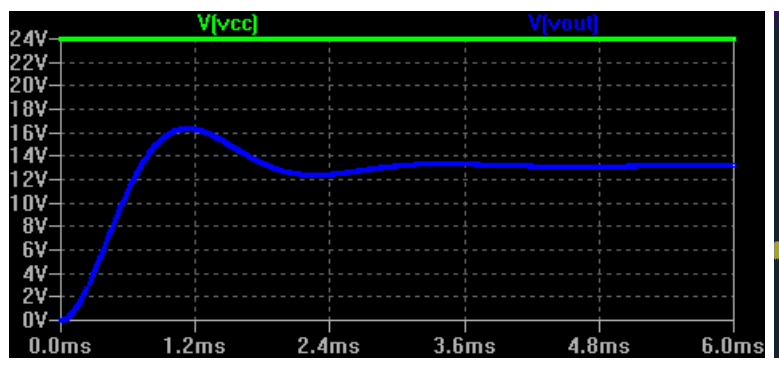

(a)

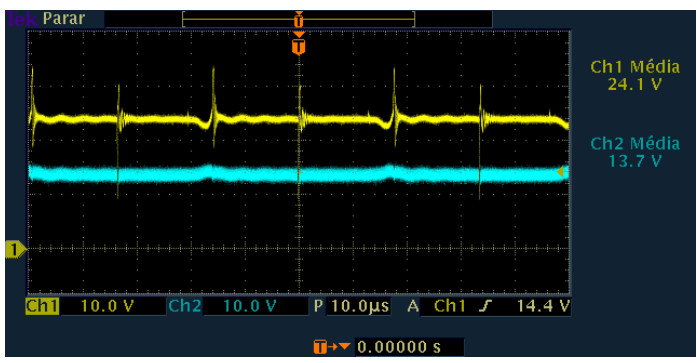

(b)

Figura 2 - (a) Sinal de Entrada (24 V) e (b) Sinal de Saída (13,5 V) do Conversor Buck

Palavras-chave: Modelagem Matemática, Conversor Buck, Eletrônica de Potência.

\section{Referências Bibliográficas}

[1] B. M. Silveira, "Design and Assembling of a Buck Converter", Trabalho de Monografia, Universidade Federal de Viçosa, 2012.

[2] V.Vopérian, "Simplified Analysis of PWM Converters using Model of PWM Switch - Part I: Continuous Current Mode.", IEEE Transactions on Aerospace and Electronics Systems, vol. 26, no. 3, Maio/1993. 